\title{
HDAC4 controls histone methylation in response to elevated cardiac load
}

\author{
Mathias Hohl,, Michael Wagner, ${ }^{1}$ Jan-Christian Reil, ${ }^{1}$ Sarah-Anne Müller, ${ }^{1}$ Marcus Tauchnitz,, \\ Angela M. Zimmer, ${ }^{1}$ Lorenz H. Lehmann, ${ }^{2}$ Gerald Thiel, ${ }^{3}$ Michael Böhm, ${ }^{1}$ \\ Johannes Backs, ${ }^{2}$ and Christoph Maack ${ }^{1}$
}

\begin{abstract}
${ }^{1}$ Klinik für Innere Medizin III, Universitätsklinikum des Saarlandes, Homburg, Germany. ${ }^{2}$ Klinik für Innere Medizin III, Universitätsklinikum Heidelberg, and German Centre for Cardiovascular Research (DZHK), Heidelberg, Germany. ${ }^{3}$ Medizinische Biochemie und Molekularbiologie, Universitätsklinikum des Saarlandes, Homburg, Germany.
\end{abstract}

\begin{abstract}
In patients with heart failure, reactivation of a fetal gene program, including atrial natriuretic peptide (ANP) and brain natriuretic peptide $(B N P)$, is a hallmark for maladaptive remodeling of the LV. The mechanisms that regulate this reactivation are incompletely understood. Histone acetylation and methylation affect the conformation of chromatin, which in turn governs the accessibility of DNA for transcription factors. Using human LV myocardium, we found that, despite nuclear export of histone deacetylase 4 (HDAC4), upregulation of ANP and $B N P$ in failing hearts did not require increased histone acetylation in the promoter regions of these genes. In contrast, di- and trimethylation of lysine 9 of histone 3 (H3K9) and binding of heterochromatin protein 1 (HP1) in the promoter regions of these genes were substantially reduced. In isolated working murine hearts, an acute increase of cardiac preload induced HDAC4 nuclear export, $\mathrm{H} 3 \mathrm{~K} 9$ demethylation, HP1 dissociation from the promoter region, and activation of the ANP gene. These processes were reversed in hearts with myocytespecific deletion of $\mathrm{Hdac} 4$. We conclude that HDAC4 plays a central role for rapid modifications of histone methylation in response to variations in cardiac load and may represent a target for pharmacological interventions to prevent maladaptive remodeling in patients with heart failure.
\end{abstract}

\section{Introduction}

Chronic heart failure affects approximately 5 million patients in the United States and carries a poor prognosis $(1,2)$. An important risk factor for development of heart failure is LV hypertrophy, which occurs in response to neurohormonal activation and increased filling pressures of the $\operatorname{LV}(1,2)$. Deterioration of cardiac function during heart failure progression is associated with activation of genes that trigger structural, functional, and electrical remodeling of the heart. In particular, the reactivation of a set of fetal genes, including atrial natriuretic peptide ( $A N P$; also known as $N p p a$ ) and brain natriuretic peptide (BNP; also known as $N p p b)$, correlates well with the clinical severity and prognosis of the disease (3-5). The mechanisms that regulate the reactivation of this fetal gene program, however, are incompletely understood.

In the nucleus, DNA is packed into chromatin. The basic building block of chromatin is the nucleosome, consisting of an octamer of 4 core histone proteins: $\mathrm{H} 2 \mathrm{a}, \mathrm{H} 2 \mathrm{~b}, \mathrm{H} 3$, and $\mathrm{H} 4$. In a condensed chromatin formation, the DNA is hardly accessible for transcription factors; thus, gene expression requires nucleosome unfolding (6). A key role in regulating chromatin structure is played by histone acetylation and methylation. While acetylation of histones - for example, at lysines 9 and 27 of histone 3 (H3K9 and H3K27, respectively) or at lysine 91 of histone 4 (H4K91) induces relaxation of chromatin, methylation can either facilitate or repress gene expression (7-10). For instance, methylation of $\mathrm{H} 3 \mathrm{~K} 4$ is associated with active genes, whereas di- and trimethylation of $\mathrm{H} 3 \mathrm{~K} 9$ ( $\mathrm{H} 3 \mathrm{~K} 9 \mathrm{me} 2$ and $\mathrm{H} 3 \mathrm{~K} 9 \mathrm{me} 3$, respectively) occur pri-

Authorship note: Michael Wagner and Jan-Christian Reil contributed equally to this work.

Conflict of interest: The authors have declared that no conflict of interest exists. Citation for this article: J Clin Invest. 2013;123(3):1359-1370. doi:10.1172/JCI61084. marily in silenced genes by creating a binding site for heterochromatin protein 1 (HP1) (9-11). It was proposed that by these and other chromatin modifications, a multifactorial "histone code" is established that governs the accessibility of DNA for transcription factors and, thus, gene expression (12).

Histone acetylation is regulated by histone acetyltransferases (HATs) and deacetylases (HDACs) (8, 13). Class II HDACs (HDAC4, HDAC5, HDAC7, and HDAC9) are highly expressed in the heart; are signal responsive; limit cardiomyocyte growth and hypertrophy; and suppress transition to heart failure $(8,14,15)$. In response to GPCR activation, $\mathrm{Ca}^{2+} /$ calmodulin-dependent kinase II (CaMKII), protein kinase $\mathrm{D}$, and reactive oxygen species mediate the export of HDAC4, HDAC5, and HDAC9 from the nucleus to the cytosol by targeted phosphorylation and/or oxidation (16-19). Nuclear class II HDACs repress gene transcription by interacting with myocyte enhancer factor 2 (MEF2), and it is perceived that at least part of its repressive function is related to keeping the respective promoter region in a deacetylated state. Nucleo-cytoplasmic shuttling relieves this repressive function $(8,16,20,21)$. Despite evidence that HATs and HDACs regulate cardiac hypertrophy, little is known about the actual epigenetic modifications induced by these enzymes, especially in the human failing heart or in response to changes in hemodynamic load.

In contrast to acetylation, histone methylation - governed by histone methyltransferases SUV39H1, G9a, and others $(9,22)$ - has long been considered to be a more permanent epigenetic mark (12). However, the discovery of histone demethylases - i.e., lysine-specific demethylase 1A (LSD1; ref. 23) and the family of JMJC domaincontaining proteins $(24)$ - substantially shifted this paradigm $(9,25)$. In fact, recent reports indicate that histone methylation is dynamically regulated in inflammatory and metabolic disorders (26-28). Furthermore, differential methylation patterns for H3K4 

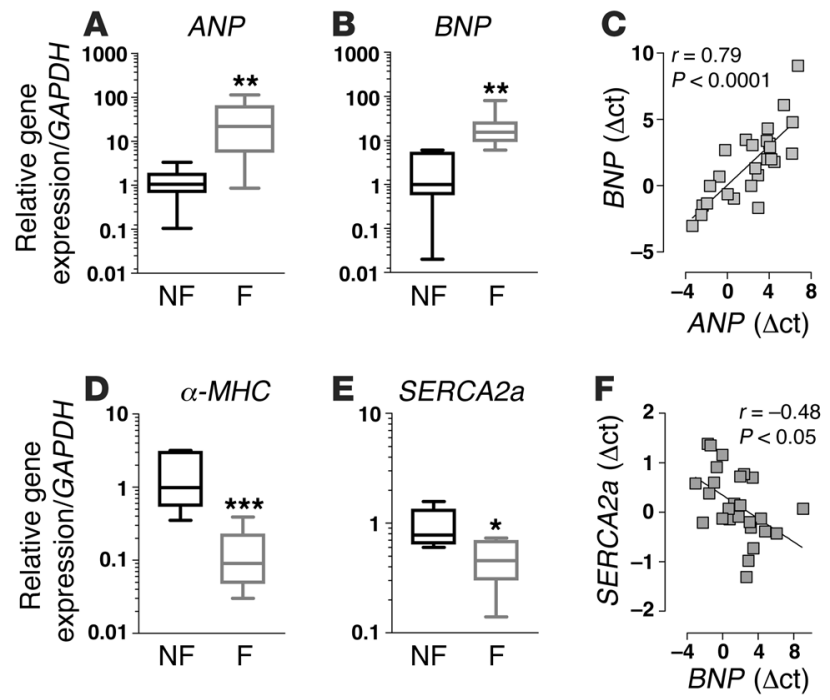

Figure 1

Reactivation of $A N P$ and $B N P$ in human failing myocardium. Gene expression of $A N P(\mathbf{A}), B N P(\mathbf{B}), \alpha-M H C(\mathbf{D})$, and SERCA2a (E) in human nonfailing (NF; $n=8)$ and failing $(\mathrm{F} ; n=16)$ myocardium. Correlation between $A N P$ and $B N P$ expression $(\mathbf{C})$ and between $B N P$ and $S E R C A 2 a$ expression $(\mathbf{F})$. Boxes denote interquartile range; lines within boxes denote median; whiskers denote range. ${ }^{*} P<0.05$, ${ }^{* \star} P<0.01$, ${ }^{* * *} P<0.005$ vs. nonfailing.

and $\mathrm{H} 3 \mathrm{~K} 9$ occur in the vicinity of various gene clusters of failing human hearts (29). Recently, an important role for JMJD2A (also known as $K D M 4 A$ ) in regulating cardiac hypertrophy in response to long-term pressure overload was revealed, governing H3K9 methylation status in the promoter region of the four-and-a-half LIM domains 1 (FHL1) gene (30). Although in that study, deletion of $J M J D 2 A$ also reduced the expression of $A N P$ and $B N P$ after pressure overload in vivo, it is unclear whether this was the result of direct epigenetic modifications in the promoter regions of these fetal genes or an indirect consequence of the reduction of cardiac hypertrophy through FHL1-related signaling and/or hemodynamics.
The present study is the first in-depth analysis of epigenetic modifications in the promoter regions of ANP and BNP in human failing and nonfailing myocardium. Despite pronounced nuclear export of HDAC4, histone acetylation was not required for ANP and BNP gene activation. In contrast, H3K9 demethylation was closely associated with reactivation of fetal genes and nuclear export of HDAC4. Experiments in genetically modified mice revealed that nuclear HDAC4 export was required for $\mathrm{H} 3 \mathrm{~K} 9$ demethylation, HP1 dissociation, and ANP gene activation in response to increased hemodynamic load. Protein-protein interaction of HDAC4 with the histone methyltransferase SUV39H1 was disrupted upon nuclear export of HDAC4 in response to targeted phosphorylation by CaMKIISB, representing a potential underlying mechanism. Furthermore, upregulation of H3K9-specific JMJC domain-containing demethylases may sustain these epigenetic modifications in the terminally failing human heart.

\section{Results}

Characteristic alterations of gene expression in human failing myocardium. Human LV myocardium was obtained from patients with terminal heart failure due to ischemic cardiomyopathy (ICM) or dilated cardiomyopathy (DCM) and compared with nonfailing donor hearts (see Supplemental Table 1; supplemental material available online with this article; doi:10.1172/JCI61084DS1). Since no differences between ICM and DCM were detected in most subsequent analyses, unless indicated otherwise, these groups were merged into a single group referred to herein as failing myocardium. As described previously (3-5), ANP and $B N P$ were upregulated in failing versus nonfailing myocardium, with a close correlation between both natriuretic peptides (Figure 1, A-C). Furthermore, mRNA expressions of $\alpha$-myosin heavy chain ( $\alpha-M H C$; also known as $M Y H 6)$ and sarcoplasmic reticulum $\mathrm{Ca}^{2+}$ ATPase (SERCA2a; also known as $A T P 2 A 2$ ) were downregulated (Figure 1, D and E), both of which are characteristic hallmarks of human heart failure (3-5). In agreement with a previous study (5), an inverse correlation was observed between BNP and SERCA2 a expression (Figure 1F).

Histone acetylation in ANP and BNP promoter regions. Since ANP and $B N P$ expression increase in response to elevated hemodynamic load, predicting clinical severity and prognosis in patients with

\section{Figure 2}

H3K27ac and H3K9ac in ANP and BNP promoter regions. Representative PCR (A and $\mathbf{C})$ and cumulative analyses (B and $\mathbf{D})$ of ChIP assay experiments probing $\mathrm{H} 3 \mathrm{~K} 9 \mathrm{ac}$ and $\mathrm{H} 3 \mathrm{~K} 27 \mathrm{ac}$ in $A N P, B N P$, and GAPDH promoter regions of nonfailing $(n=8)$ and failing $(n=16)$ myocardium. Input shows PCR product of total chromatin without prior IP; no Ab added served as a negative control. ChIP assay experiments on human nonfailing and failing myocardium were performed at the same time with identical conditions, and amplified PCR products performed with specific oligonucleotides directed against $A N P, B N P$, or GAPDH promoter regions were separated on the same agarose gel. ${ }^{*} P<0.05,{ }^{* *} P<0.01$ vs. GAPDH; ${ }^{\dagger} P<0.05$ vs. nonfailing.
A
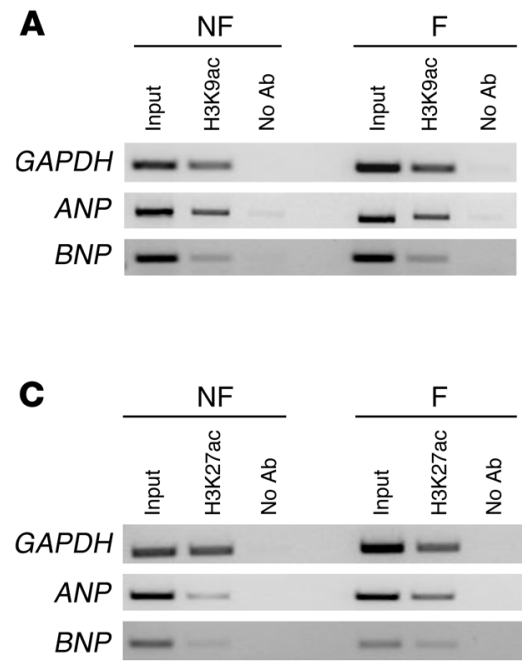

B

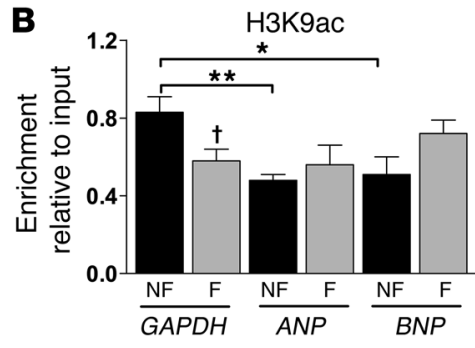

D

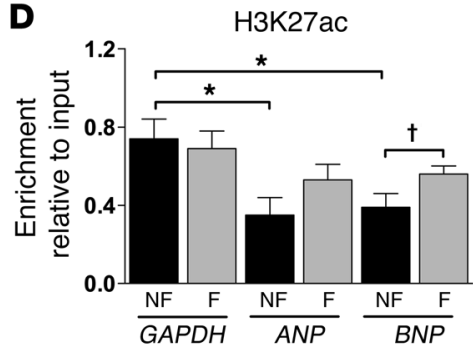



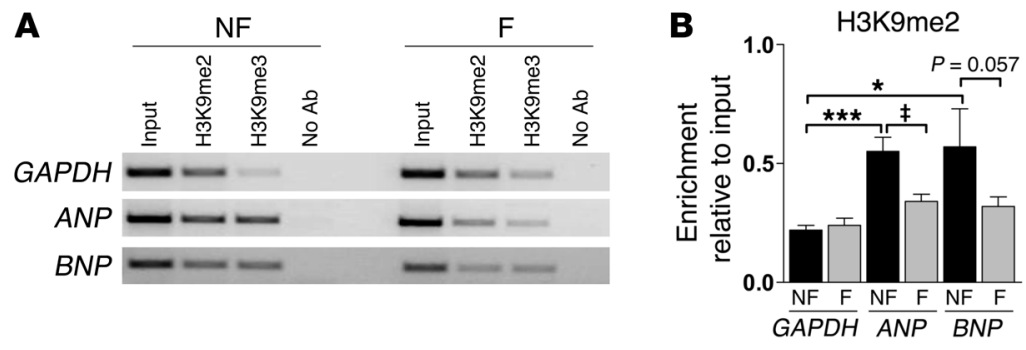

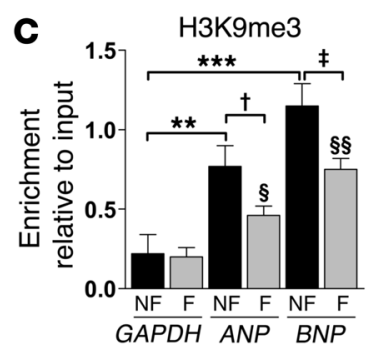

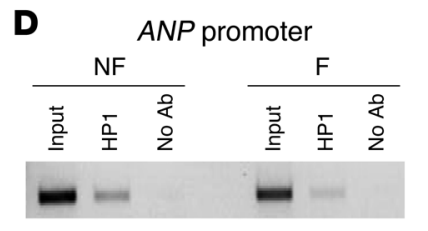

E

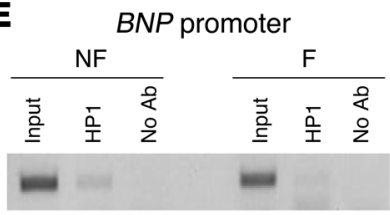

$\mathbf{F}$

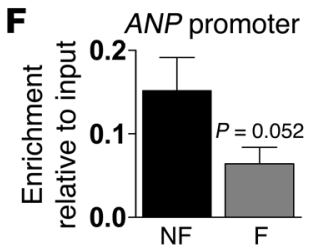

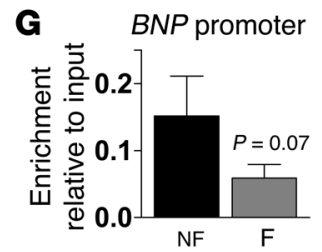

H

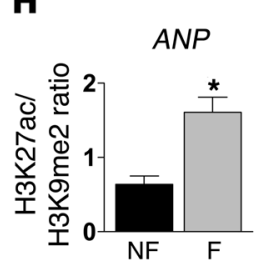

I

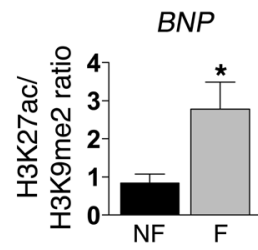

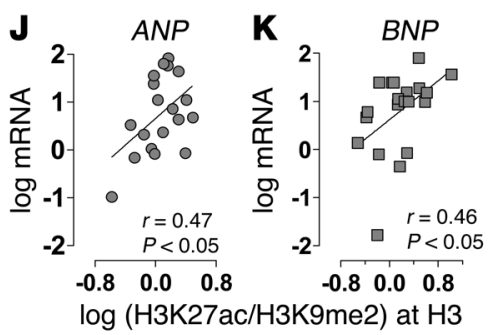

Figure 3

H3K9 demethylation and HP1 dissociation in ANP and BNP promoter regions of failing myocardium. Representative PCR of ChIP assay experiments probing $\mathrm{H} 3 \mathrm{~K} 9 \mathrm{me} 2$ and $\mathrm{H} 3 \mathrm{~K} 9 \mathrm{me} 3(\mathbf{A})$, and cumulative analyses (B and C; nonfailing, $n=8$; failing, $n=16$ ). Representative PCR of ChIP probing for HP1 binding to the ANP (D) and BNP promoter (E), and cumulative analyses ( $\mathbf{F}$ and $\mathbf{G}$; nonfailing, $n=8$; failing, $n=16)$. The ratio between H3K27ac and $\mathrm{H} 3 \mathrm{~K} 9 \mathrm{me} 2$ in the promoter regions of $A N P(\mathbf{H})$ and $B N P(\mathbf{I})$ was calculated in nonfailing $(n=8)$ and failing $(n=16)$ myocardium and correlated with $A N P(\mathbf{J})$ and $B N P(\mathbf{K})$ gene expression. ChIP assay experiments on human nonfailing and failing myocardium were performed at the same time with identical conditions, and amplified PCR products performed with specific oligonucleotides directed against $A N P$, $B N P$, or GAPDH promoter regions were separated on the same agarose gel. ${ }^{*} P<0.05,{ }^{* \star} P<0.01,{ }^{* *} P<0.001$ vs. GAPDH nonfailing; ${ }^{\dagger} P<0.05$, $\ddagger P<0.01$, failing vs. nonfailing; $\S P<0.05, \S \S P<0.01$ vs. GAPDH failing.

heart failure, we analyzed histone acetylation and methylation patterns in the promoter regions of these genes by ChIP (Figure 2A and Supplemental Figure 1, A and B). The promoter regions of the housekeeping (and thus active) gene GAPDH served as an internal control. In nonfailing myocardium, the promoter regions of ANP and $B N P$ showed less acetylation at $\mathrm{H} 3 \mathrm{~K} 9$ and $\mathrm{H} 3 \mathrm{~K} 27$ (H3K9ac and $\mathrm{H} 3 \mathrm{~K} 27 \mathrm{ac}$, respectively) than those of GAPDH (Figure 2, A-D). While H3K9ac was unchanged (Figure 2, A and B), H3K27ac was modestly increased in the $B N P$ (but not $A N P$ ) promoter region of failing versus nonfailing myocardium (Figure 2, C and D), in favor of a slightly more relaxed chromatin structure. H4K91ac, however, was similar in GAPDH, $A N P$, and $B N P$ promoter regions and was not affected in failing myocardium (Supplemental Figure 2A).

Histone methylation in ANP and BNP promoter regions. Another epigenetic mark of active genes is methylation of $\mathrm{H} 3 \mathrm{~K} 4$, whereas $\mathrm{H} 3 \mathrm{~K} 9 \mathrm{me} 2$ and $\mathrm{H} 3 \mathrm{~K} 9 \mathrm{me} 3$ induce gene silencing (10). In nonfailing myocardium, $\mathrm{H} 3 \mathrm{~K} 9 \mathrm{me} 2$ and $\mathrm{H} 3 \mathrm{~K} 9 \mathrm{me} 3$ were more pronounced in the promoter regions of $A N P$ and $B N P$ compared with GAPDH (Figure 3, A-C). In failing myocardium, however, H3K9me2 and $\mathrm{H} 3 \mathrm{~K} 9 \mathrm{me} 3$ were reduced in $A N P$ and $B N P$ promoter regions, favoring an open chromatin formation (Figure 3, A-C). In contrast, $\mathrm{H} 3 \mathrm{~K} 4 \mathrm{me} 2$ and $\mathrm{H} 3 \mathrm{~K} 4 \mathrm{me} 3$ did not change in failing versus nonfailing myocardium (Supplemental Figure 2, B-D). Since H3K9me3 is a binding site for HP1 (11), we analyzed HP1 binding to the promoter regions of $A N P$ and $B N P$ by ChIP assays. In agreement with demethylation of $\mathrm{H} 3 \mathrm{~K} 9, \mathrm{HP} 1$ binding was reduced in failing versus nonfailing myocardium (Figure 3, D-G).

The changes of $\mathrm{H} 3 \mathrm{~K} 9$ methylation status alone did not correlate to the variations in ANP and BNP expression. However, since the combination of various epigenetic marks may determine a histone code governing accessibility of the DNA for transcription factors (12), we determined the ratio of those marks that were (at least partially) modified in human failing myocardium: namely, H3K27ac (Figure 2D) divided by H3K9me2 (Figure 3B). This ratio was increased in both $A N P$ and $B N P$ promoter regions of failing myocardium and correlated with increased $A N P$ and $B N P$ expression (Figure 3, $\mathrm{H}-\mathrm{K}$ ).

Upregulation of JMJC domain-containing demethylases in buman heart failure. Since changes in histone methylation were more prominent than changes in histone acetylation, we set out to analyze the underlying mechanisms for $\mathrm{H} 3 \mathrm{~K} 9$ demethylation in failing hearts. Methylation status is balanced by activities of histone methyltransferases (G9a and SUV39H1) and histone demethylases (LSD1; JMJD1, also known as KDM3A; and JMJD2) (9, 22-25). While mRNA expression of G9a, SUV39H1, and LSD1 was unchanged (Supplemental Figure 3), expression of JMJD1A, JMJD2A, and JMJD2B was 2- to 2.5-fold upregulated in failing versus nonfailing myocardium (Figure 4, 

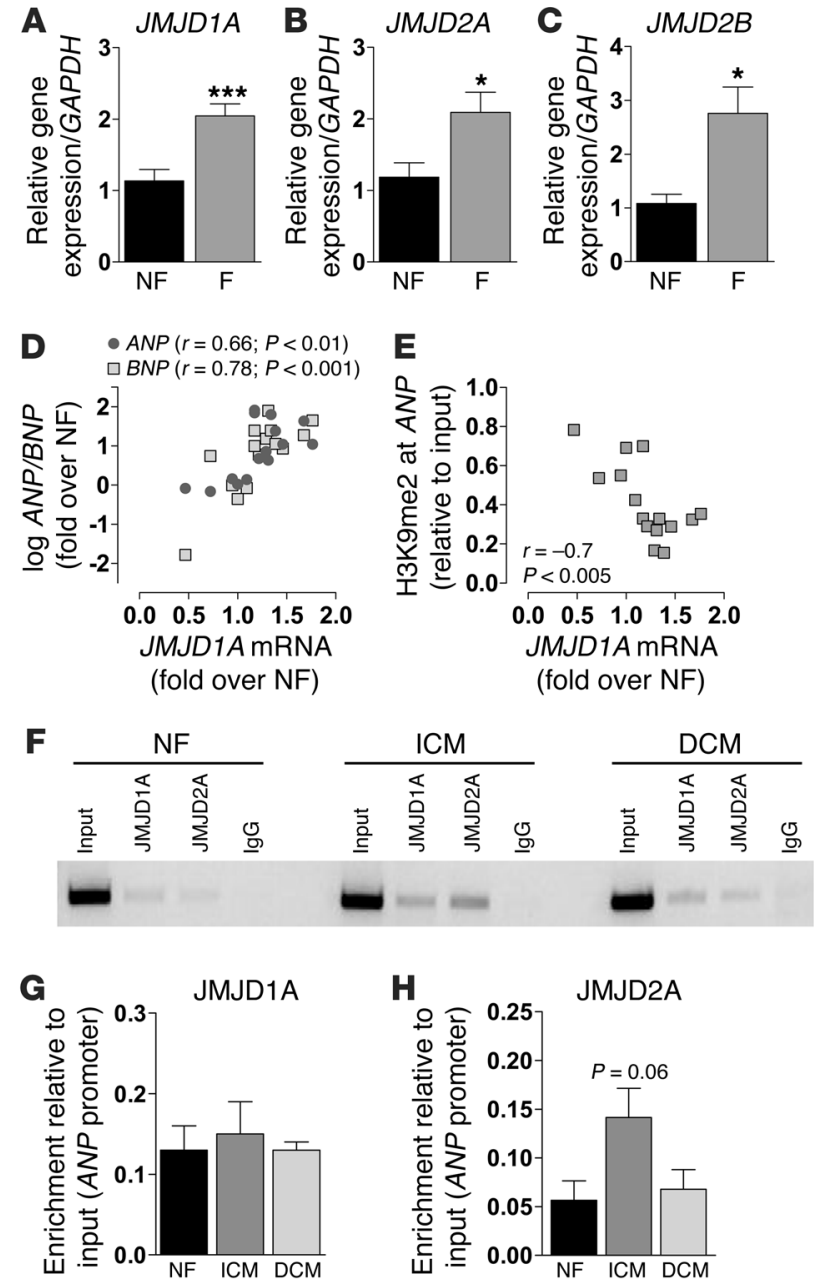

A-C). Upregulation of JMJD1A correlated positively with increased $A N P$ and $B N P$ expression and inversely with $\mathrm{H} 3 \mathrm{~K} 9 \mathrm{me} 2$ in the promoter region of $A N P$ (Figure 4, D and E). ChIP assays revealed that both JMJD1A and JMJD2A bound to the promoter regions of ANP in nonfailing and failing myocardium of patients with ICM or DCM (Figure $4 \mathrm{~F}$ ). An increased recruitment to the ANP promoter region was detected for JMJD2A in myocardium of patients with ICM, but not patients with DCM, while JMJD1A recruitment was unchanged (Figure 4, F-H). ChIP assays with LSD1, SUV39H1, and G9a indicated that direct binding of these histone-modifying enzymes to the promoter regions was weak and not differentially regulated between failing and nonfailing myocardium (data not shown).

Nuclear export of HDAC4 correlates with $\mathrm{H} 3 \mathrm{~K} 9$ demethylation and upregulation of fetal genes in human failing myocardium. Recruitment of G9a, SUV39H1, and LSD1 to the DNA requires other regulatory proteins, such as REST (for G9a, SUV39H1, and LSD1) and/ or HDAC4 (for HP1 and possibly SUV39H1), both of which have been associated with regulation of fetal genes in the heart $(8,14,15$, 31,32 ). However, we did not observe any regulatory role for REST in human failing myocardium (see Supplemental Results and Discussion and Supplemental Figure 4). Thus, we focused on a possible role of HDAC4 for histone methylation. Under in vitro conditions in cellular expression systems, H3K9 methylation is governed by a corepressor complex consisting of HDAC4 and HP1 (33), and HP1

\section{Figure 4}

Upregulation of JMJC domain-containing demethylases in human failing myocardium. mRNA expression of histone demethylases JMJD1A $(\mathbf{A}), J M J D 2 A(B)$, and JMJD2B (C) in nonfailing $(n=8)$ and failing $(n=16)$ myocardium. Correlation between JMJD1A mRNA and ANP or BNP mRNA expression (D) and H3K9me2 in the promoter region of $A N P(E)$. Representative PCR (F) of ChIP assay experiments and cumulative analyses probing JMJD1A $(\mathbf{G})$ and JMJD2A $(\mathbf{H})$ binding to the ANP promoter ( $n=5$ [nonfailing]; 6 [ICM and DCM]). ChIP assay experiments on human nonfailing and failing myocardium were performed at the same time with identical conditions, and amplified PCR products performed with specific oligonucleotides directed against $A N P, B N P$, or GAPDH promoter regions were separated on the same agarose gel. ${ }^{*} P<0.05,{ }^{\star * *} P<0.001$ vs. nonfailing.

was previously shown to interact with SUV39H1 (34). Since HDAC4 is selectively targeted by CaMKIISB (17), and CaMKII activity is upregulated in human failing hearts (35), we sought to determine whether H3K9 demethylation (Figure 3, A-C), HP1 dissociation from $A N P$ and $B N P$ promoter regions (Figure $3, \mathrm{D}-\mathrm{G}$ ), and $A N P$ and $B N P$ upregulation (Figure 1, A and $\mathrm{B}$ ) could be related to nuclear export of HDAC4. While similar amounts of HDAC4 were detected in the cytosolic and nuclear protein fractions of nonfailing myocardium, a 4-fold shift of the cytosolic/nuclear ratio of HDAC4 protein expression was observed in failing myocardium (Figure 5, A-C). This nucleo-cytoplasmic shuttling of HDAC4 correlated inversely with $\mathrm{H} 3 \mathrm{~K} 9 \mathrm{me} 2$ levels in the promoter regions of $A N P$ and $B N P$ and positively with ANP and BNP expression (Figure 5, D and E).

Taken together, these findings suggest that in human failing myocardium, H3K9 demethylation, rather than increased histone acetylation, in the promoter regions of $A N P$ and $B N P$ is associated with upregulation of these fetal cardiac genes. Furthermore, our data suggest that nuclear export of HDAC4 and/or upregulation of JMJD1A, JMJD2A, and JMJD2B could be potential underlying mechanisms for H3K9 demethylation.

Role of JMJD1A and JMJD2A for regulation of fetal genes. To determine whether changes in JMJD1A and JMJD2A expression affect gene activation of $A N P$ and $B N P$, we performed experiments in isolated rat neonatal and adult cardiac myocytes. As expected, mRNA expression of $A N P$ and $B N P$ was 80 - and 7-fold higher, respectively, in neonatal versus adult rat cardiac myocytes (Figure 6A). Interestingly, $J M J D 1 A$ and JMJD2A expression was also increased 4- and 9-fold, respectively, in neonatal versus adult cardiac myocytes. Accordingly, expression of a known target gene of JMJD2A, FHL1 (30), was also increased 7-fold, while SERCA2 a expression was reduced 3-fold. In agreement with elevated JMJD1A and JMJD2A expression, H3K9me2 and $\mathrm{H} 3 \mathrm{~K} 9 \mathrm{me} 3$ were reduced in the $A N P$ and $B N P$ promoter regions in neonatal versus adult cardiomyocytes (Figure 6B).

Downregulation of either JMJD1A or JMJD2A by siRNA in neonatal cardiac myocytes led to compensatory upregulation of the other JMJD isoform and had no effect on ANP or BNP expression (data not shown). In light of this finding, and because both JMJD1A and $J M J D 2 A$ were upregulated in concert in human heart failure, we applied simultaneous JMJD1A and JMJD2A siRNA (Figure 6C). This JMJD1A and JMJD2A double knockdown (by $20 \%$ and $45 \%$, respectively; Figure $6 \mathrm{D}$ ) resulted in moderate but consistent downregulation of $A N P$ and $B N P$ expression (by $13 \%$ and $15 \%$, respectively; Figure 6E). The degree of $A N P$ and $B N P$ downregulation correlated with the degree of $J M J D 1 A$ knockdown $(r=0.39$ and $r=0.54$; $P<0.05$ and $P<0.005$, respectively) and $J M J D 2 A$ knockdown 
A

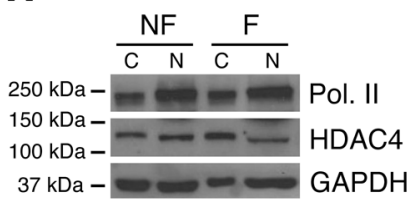

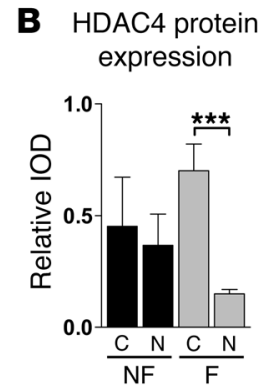
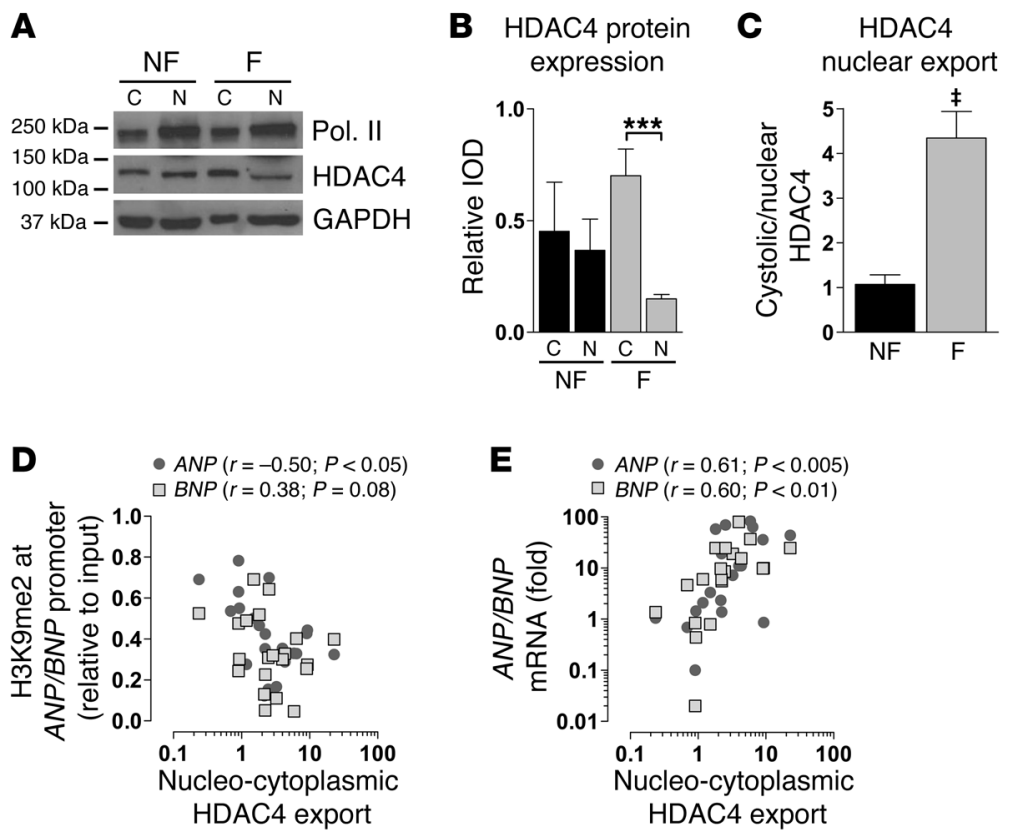

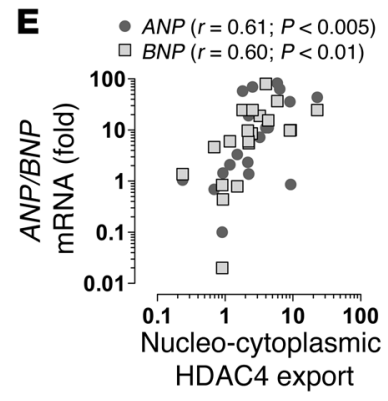

\section{Figure 5}

Increased nucleo-cytoplasmic shuttling of HDAC4 in failing myocardium. Representative (A) and cumulative (B) results of Western blot analyses of HDAC4, mRNA polymerase II (Pol. II), and GAPDH in cytosolic (C) and nuclear $(\mathrm{N})$ protein fractions of human nonfailing $(n=8)$ and failing ( $n=16)$ myocardium. Nuclear protein expression was related to mRNA polymerase II, while cytosolic expression was related to GAPDH. Nucleo-cytoplasmic shuttling of HDAC4 was quantified by the cytosolic/ nuclear ratio of HDAC4 expression (C). Correlation of nucleo-cytoplasmic shuttling of HDAC4 with $\mathrm{H} 3 \mathrm{~K} 9$ me2 at $A N P$ and $B N P$ promoter regions (D) and $A N P$ and $B N P$ expression $(\mathbf{E})$ in nonfailing and failing myocardium. ${ }^{* *} P<0.001$, cytosolic vs. nuclear; ${ }^{\ddagger} P<0.001$, failing vs. nonfailing. $(r=0.43$ and $r=0.67 ; P<0.05$ and $P<0.0005$, respectively). Accordingly, $\mathrm{H} 3 \mathrm{~K} 9 \mathrm{me} 2$ and $\mathrm{H} 3 \mathrm{~K} 9 \mathrm{me} 3$ in the promoter regions of $A N P$ and $B N P$ increased after $J M J D 1 A$ and JMJD2A double knockdown (Figure 6, F-H). These data indicate that varying expression of $J M J D 1 A$ and JMJD2A is sufficient to affect ANP and BNP gene expression through variations of $\mathrm{H} 3 \mathrm{~K} 9 \mathrm{me} 2$ and $\mathrm{H} 3 \mathrm{~K} 9 \mathrm{me} 3$ status in these promoter regions in cardiac myocytes.

Lack of JMJD1 and JMJD2 upregulation in response to pressure overload in mice. To determine whether JMJD1A and JMJD2A upregulation is not only sufficient, but also necessary, for ANP upregulation during cardiac hypertrophy, we performed thoracoaortic constriction (TAC) in C57BL/6NCrl mice for 6 weeks. Despite an increase in heart weight/BW ratio and robust upregulation of ANP after TAC, expression of JMJD1A and JMJD2A was unaltered (Supplemental Figure 5, A-D). In contrast, nucleo-cytoplasmic shuttling of HDAC4 was observed after TAC (Supplemental Figure 5E). Together with the data in cardiac myocytes (Figure 6), these data indicate that although variations in JMJD1A and JMJD2A expression are sufficient, they are not necessary for $A N P$ regulation in the heart.

Epigenetic changes in response to elevated preload and afterload in isolated working hearts. In the heart, expression of ANP and BNP correlates with LV wall stress, and cardiac pre- and afterload are both elevated in patients with heart failure. To determine whether hemodynamic changes directly induce epigenetic remodeling, and to further elucidate the underlying regulatory mechanisms, isolated mouse hearts were exposed to physiological pre- and afterload (10 and $80 \mathrm{mmHg}$, respectively) in a working heart apparatus. After equilibration, either preload was elevated from 10 to 30 $\mathrm{mmHg}$ or afterload was elevated from 80 to $120 \mathrm{mmHg}$ for up to 90 minutes (Figure 7, A-C). These hearts were compared with a control group with maintained physiological load conditions.

Elevation of either preload or afterload increased expression of ANP after 30 minutes, with sustained expression after 60 and 90 minutes, respectively (Figure 7, D and E). This was paralleled by nucleo-cytoplasmic shuttling of HDAC4, with a correlation between ANP upregulation and nuclear HDAC4 export (Figure 7,
F-I). In contrast, neither mRNA expression of JMJD2A nor binding of JMJD2A to the ANP promoter region changed after elevation of preload (Supplemental Figure 6). Despite nuclear export of HDAC4, H3K9ac and $\mathrm{H} 3 \mathrm{~K} 27 \mathrm{ac}$ did not change in response to elevated pre- or afterload even after 90 minutes (Supplemental Figure 7). In contrast, $\mathrm{H} 3 \mathrm{~K} 9 \mathrm{me} 2$ and $\mathrm{H} 3 \mathrm{~K} 9 \mathrm{me} 3$, but not $\mathrm{H} 3 \mathrm{~K} 27 \mathrm{me} 3$, decreased in response to elevated preload after 60 minutes (Figure 8, A and C-E, and data not shown). Accordingly, HP1 dissociated from the ANP promoter region after an increase of preload (Figure $8, \mathrm{~B}$ and F). Similar changes were observed after an increase of afterload, although these changes were slightly less pronounced (Supplemental Figure 8). These data indicate that an increase in cardiac preload induces rapid nucleo-cytoplasmic shuttling of HDAC4 and H3K9 demethylation in the promoter region of ANP, with subsequent HP1 dissociation and gene activation.

HDAC4 mediates preload-induced H3K9 demethylation and ANP upregulation. To test whether HDAC4 is causally involved in $\mathrm{H} 3 \mathrm{~K} 9$ demethylation in the $A N P$ and $B N P$ promoter regions in response to variations of workload, we used mice with cardiomyocyte-specific deletion of Hdac4 (referred to herein as HDAC4-KO mice) and WT littermate controls. Western blot experiments confirmed the absence of HDAC4 in LV myocardium of HDAC4-KO mice (Figure 9A). Under physiological load conditions, these mice had similar LV systolic and diastolic function during working heart analysis (Figure 9, B and C). In WT mice, an increase in preload induced nucleo-cytoplasmic shuttling of HDAC4 (Figure 9D). In HDAC4KO mice, baseline H3K9 and H3K27 methylation in the ANP promoter region was reduced compared with WT mice, while H3K9ac and H3K27ac were unchanged (Figure 9E and Supplemental Figure 9). After elevating preload, $\mathrm{H} 3 \mathrm{~K} 9 \mathrm{me} 2$ and $\mathrm{H} 3 \mathrm{~K} 9 \mathrm{me} 3$ paradoxically increased in HDAC4-KO mice, while they decreased in WT mice (Figure 9, E-G). There was also a trend toward increased $\mathrm{H} 3 \mathrm{~K} 27 \mathrm{me} 3$ in HDAC4-KO mice (Figure 9H). In contrast, H3K9ac and $\mathrm{H} 3 \mathrm{~K} 27 \mathrm{ac}$ were not upregulated in WT or HDAC4-KO mice after an increase in preload (Supplemental Figure 9). In agreement with the divergent preload-induced effects on H3K9 meth- 

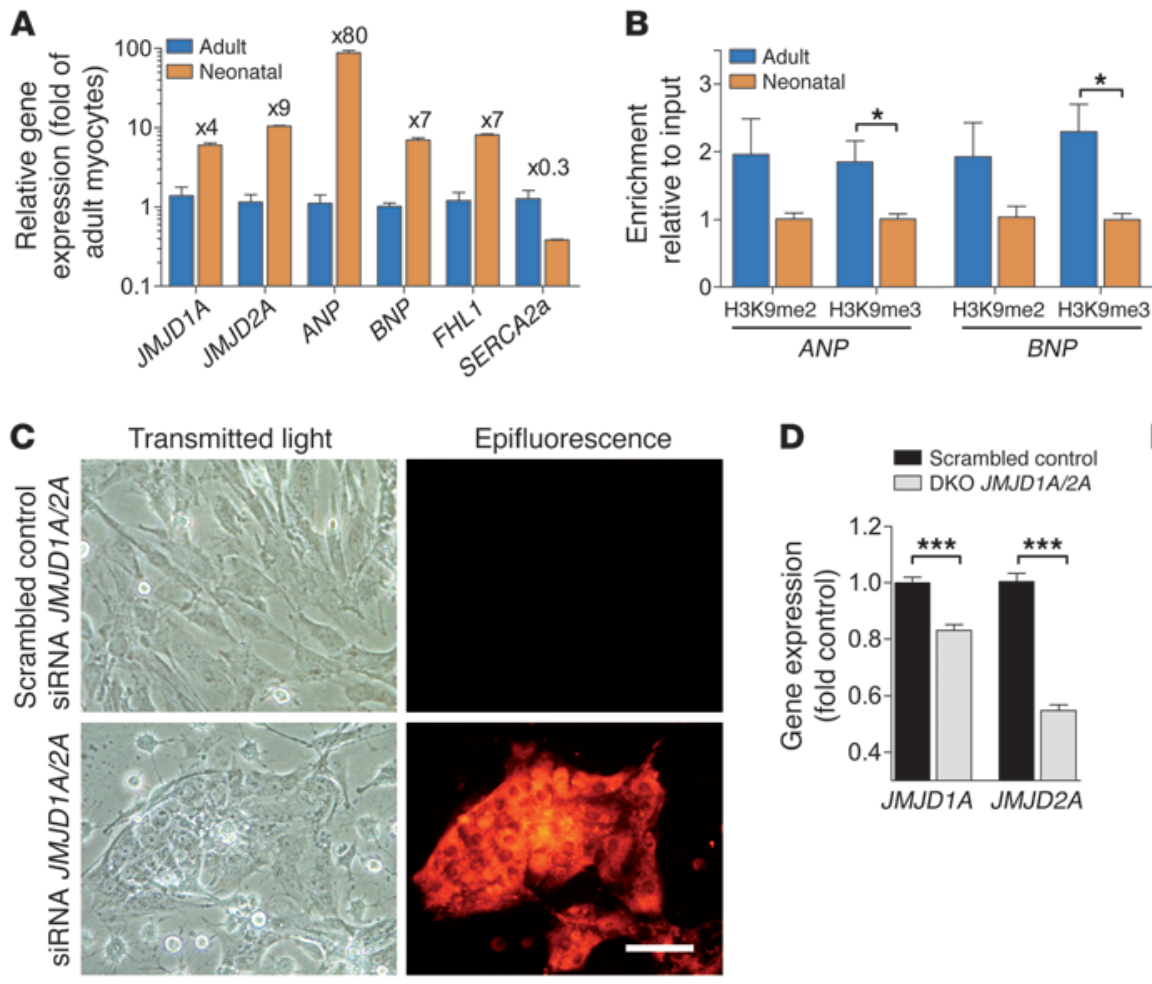

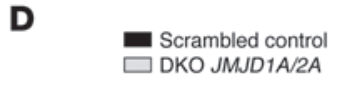

E

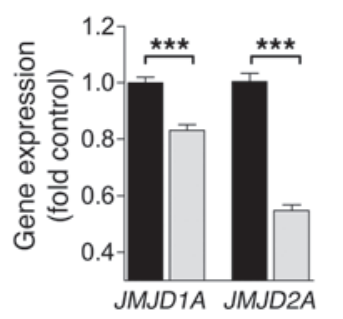

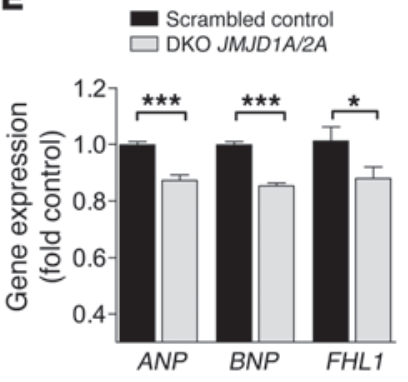

$\mathbf{F}$

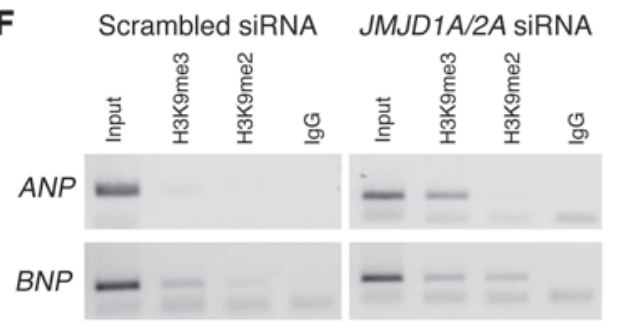

G

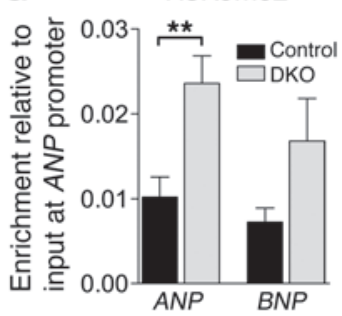

H H3K9me3

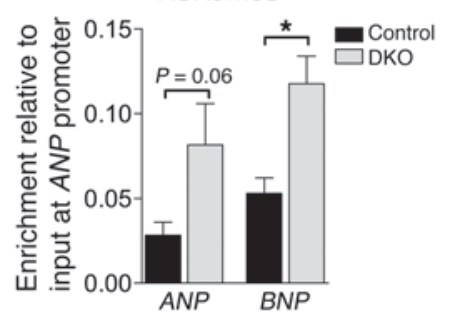

\section{Figure 6}

JMJD1A and JMJD2A regulate ANP and BNP expression. (A) mRNA expression of JMJD1A, JMJD2A, ANP, BNP, FHL1, and SERCA2a in adult $(n=4)$ and neonatal $(n=6)$ cardiac myocytes. (B) Real-time PCR analysis of ChIP assay experiments probing H3K9me2 and H3K9me3 in the $A N P$ and BNP promoter regions. (C) Transmitted light and epifluorescence images of neonatal myocytes transfected with siRNA against JMJD1A and $J M J D 2 B$, linked to the expression of red fluorescent protein or scrambled control siRNA. Scale bar: $100 \mu \mathrm{m}$. Cumulative results for mRNA expression of JMJD1A and JMJD2A (D) and ANP, BNP, and FHL1 (E) ( $n=4$ per group). Representative PCR of ChIP assay experiments (F) and cumulative analyses probing $\mathrm{H} 3 \mathrm{~K} 9 \mathrm{me} 2(\mathbf{G})$ and $\mathrm{H} 3 \mathrm{~K} 9 \mathrm{me} 3(\mathbf{H})$ in $A N P$ and $B N P$ promoter regions $(n=3-5)$. ChIP assay experiments on cells treated with scrambled or JMJD1A and JMJD2B siRNA were performed at the same time with identical conditions, and amplified PCR products performed with specific oligonucleotides directed against ANP or BNP promoter regions were separated on the same agarose gel. Lanes in $\mathbf{F}$ were run on the same gel but were noncontiguous (white lines). ${ }^{\star} P<0.05,{ }^{\star \star} P<0.01,{ }^{\star \star \star} P<0.0001$.

ylation, HP1 binding to the promoter region of ANP decreased in WT mice, but increased in HDAC4-KO mice (Figure 9, I and J). Under basal conditions, expression of ANP was 6-fold elevated in HDAC4-KO versus WT hearts, and preload-induced upregulation of ANP was completely blunted in HDAC4-KO compared with WT mice (Figure 9K). Taken together, these data indicate that HDAC4 plays a causal role in regulating the $\mathrm{H} 3 \mathrm{~K} 9$ methylation status of $A N P$ promoter and gene expression in an HP1-dependent manner.

HDAC4 interaction with SUV39H1 is disrupted by CaMKIISB. To further investigate the underlying mechanism by which HDAC4 regulates $\mathrm{H} 3 \mathrm{~K} 9$ methylation, we cotransfected COS cells with GFPtagged HDAC4 and FLAG-tagged SUV39H1, using a secondary anti- body coupled to Texas Red, in the absence and presence of a consti-

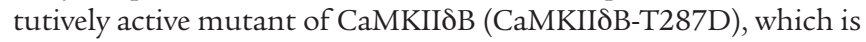
known to selectively target and phosphorylate HDAC4 (17). Under control conditions, both HDAC4 and SUV39H1 were located primarily in the nucleus (Figure 10, A-C). The yellow staining visible in the merged image (Figure 10A) suggests colocalization of both proteins. In response to CaMKIIסB-T287D, HDAC4 was exported from the nucleus to the cytosol and appeared in a characteristic punctuate pattern (Figure 10, A and B). In contrast, SUV39H1 remained in the nucleus, but its distribution changed from a homogeneous pattern under control conditions to a more punctuate one in response to CaMKIISB-T287D (Figure 10, A and C). 

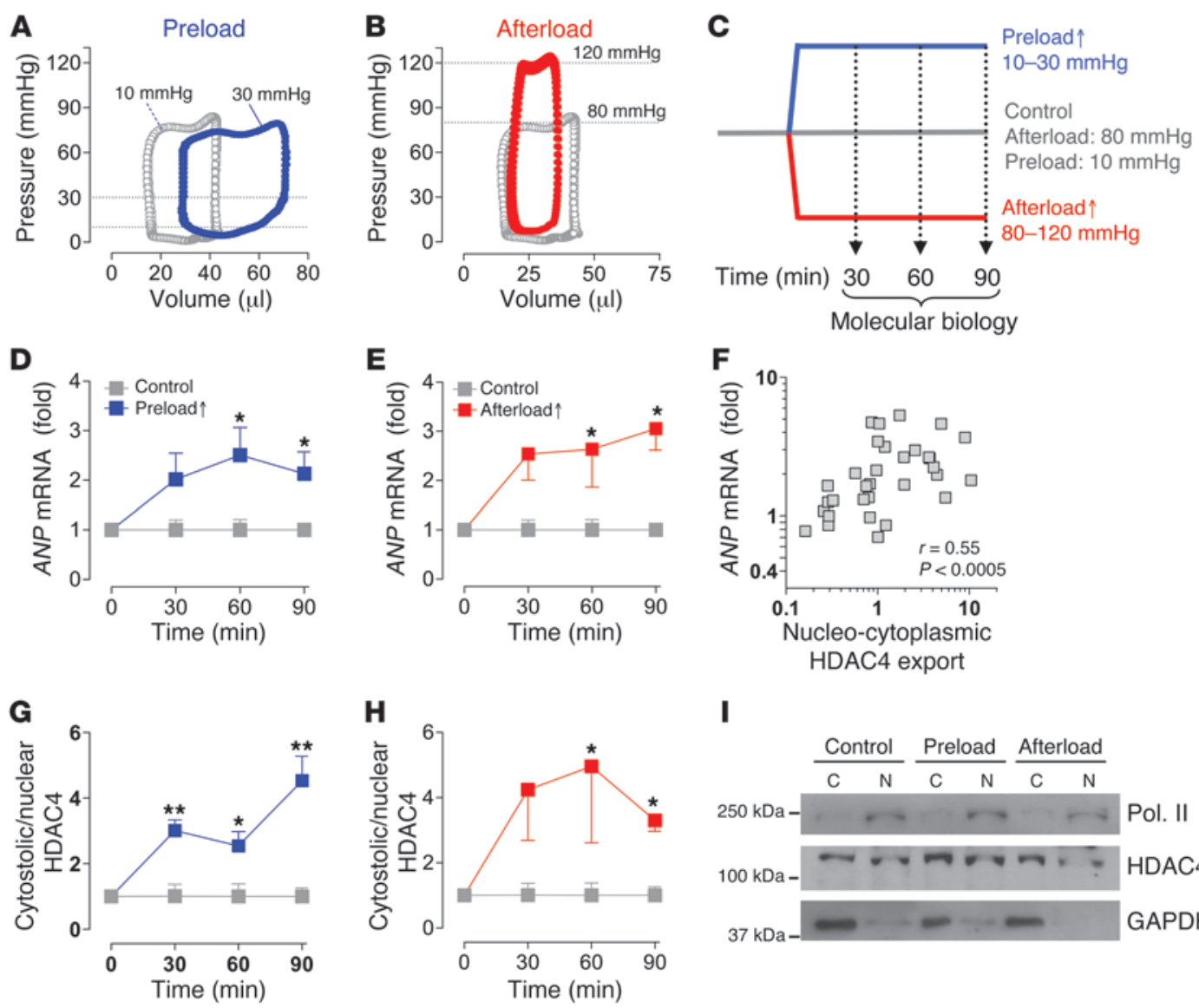

I

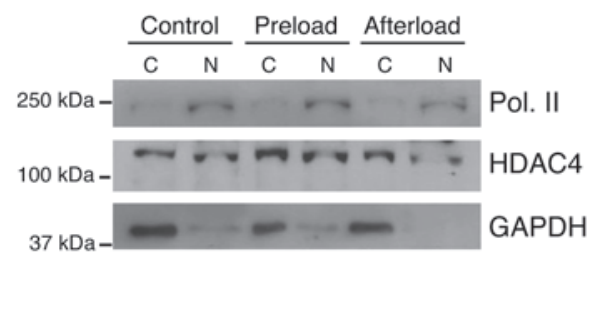

\section{Figure 7}

Acutely increased hemodynamic load induces ANP gene activation and nuclear export of HDAC4 in mouse hearts. Representative pressurevolume loops before and after an increase of preload from 10 to $30 \mathrm{mmHg}(\mathbf{A})$ or afterload from 80 to $120 \mathrm{mmHg}(\mathbf{B})$ in hearts mounted in a working-heart apparatus. Timeline and experimental design (C). Time course of ANP gene expression in mouse hearts subjected to increased preload (D) or afterload (E) vs. control ( $n=5$ per time point and group). Correlation between nucleo-cytoplasmic shuttling of HDAC4 and ANP mRNA expression $(\mathbf{F})$. Time course of nucleo-cytoplasmic shuttling of HDAC4 in response to elevated preload $(\mathbf{G})$ or afterload $(\mathbf{H})$ compared with control. Representative Western blot analysis of HDAC4, mRNA polymerase II, and GAPDH in cytosolic and nuclear protein fractions in LV myocardium from mice under control conditions or subjected to increased preload or afterload for 60 minutes $(\mathrm{I}) .{ }^{\star} P<0.05$, ${ }^{\star \star} P<0.01 \mathrm{vs}$. control.

Accordingly, colocalization between HDAC4 and SUV39H1 was disrupted by CaMKIISB-T287D (Figure 10A).

To test whether HDAC4 physically interacts with SUV39H1, we cotransfected HEK293T cells with Myc-tagged HDAC4 and FLAGtagged SUV39H1 and performed co-IP experiments. Under control conditions, we observed protein-protein interaction between HDAC4 and SUV39H1, which was reduced in response to CaMKIISB-T287D (Figure 10, D and E). These data indicate that HDAC4 physically interacts with SUV39H1 in the nucleus and that this interaction is disrupted after CaMKIISB-induced phosphorylation of HDAC4. Together with our findings in HDAC4-KO mice (Figure 9), these data suggest that preload-induced nucleo-cytoplasmic shuttling of HDAC4 induces H3K9 demethylation in the ANP and BNP promoter regions, possibly through disruption of the interaction between HDAC4 and the histone methyltransferase SUV39H1.

\section{Discussion}

Despite a plethora of knowledge on the roles of histone acetyltransferases and deacetylases in regulating cardiac hypertrophy and failure $(8,14-21)$, surprisingly little information is available on their actual ensuing epigenetic modifications. This is the first study on human myocardium that comprehensively analyzes histone modifications in the promoter regions of genes that are activated during cardiac remodeling in patients with heart failure, i.e., ANP and BNP (3-5). Unexpectedly, despite pronounced nuclear export of HDAC4 in failing hearts, no major changes in histone acetylation were observed in the promoter regions of these genes. In contrast, substantial H3K9 demethylation and HP1 dissociation occurred, predicting an open chromatin formation $(7-10,12)$. Our data in human myocardium and genetically modified mouse hearts and cell systems indicated that as a central mechanism, nucleo-cytoplasmic shuttling of HDAC4 occurs early after an increase of hemodynamic load and accounts for H3K9 demethylation, HP1 dissociation from the promoter region, and ANP gene activation. Under basal conditions, HDAC4 was associated with the histone methyltransferase SUV39H1, and this association was disrupted after CaMKIISB-induced phosphorylation of HDAC4 with subsequent nucleo-cytoplasmic shuttling. Although this does not prove a causal relationship, we propose that HDAC4 may function to recruit SUV39H1 to the promoter 


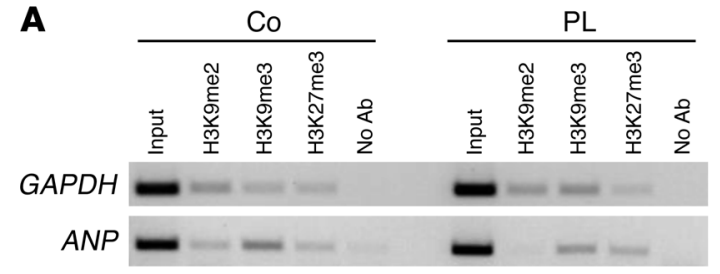

B
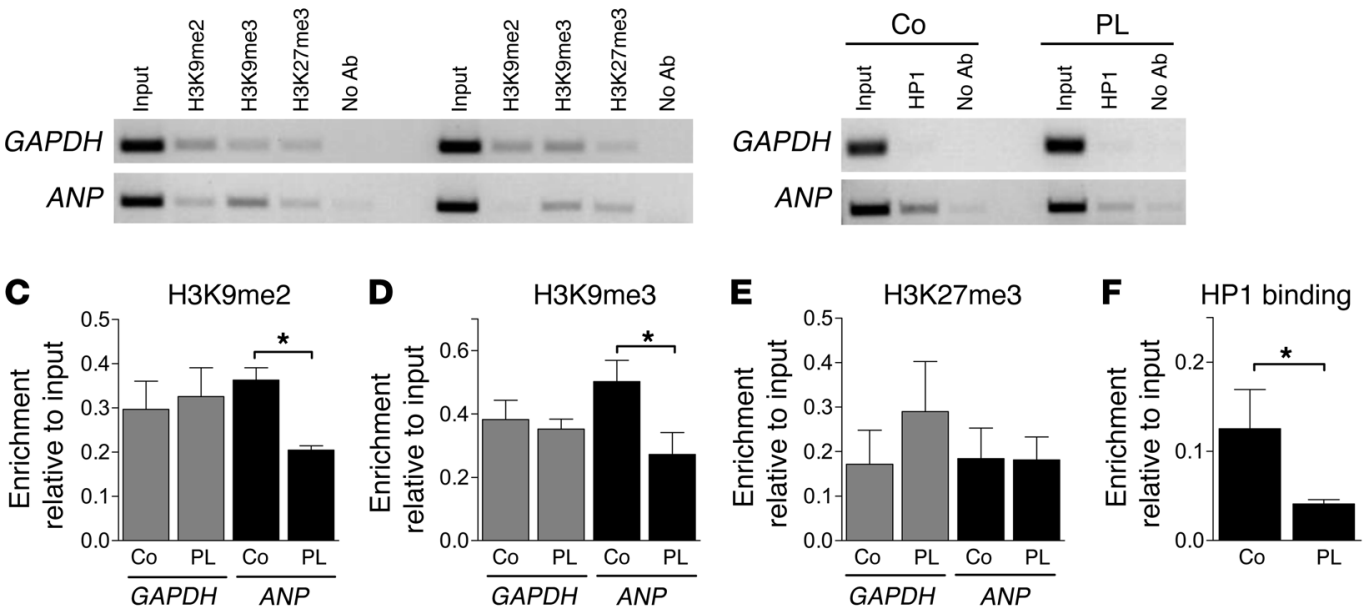

Figure 8

Elevated preload induces H3K9 demethylation in - and HP1 dissociation from - the promoter region of ANP. Representative ChIP assay experiments probing $\mathrm{H} 3 \mathrm{~K} 9 \mathrm{me} 2, \mathrm{H} 3 \mathrm{~K} 9 \mathrm{me}$, and $\mathrm{H} 3 \mathrm{~K} 27 \mathrm{me} 3(\mathbf{A})$ and $\mathrm{HP} 1$ binding $(\mathbf{B})$ at the promoter region of ANP after an elevation of preload $(\mathrm{PL})$ for 60 minutes compared with control (Co) condition. (C-F) Cumulative results of 4-6 experiments. ChIP assay experiments on hearts with normal and elevated preload were performed at the same time with identical conditions, and amplified PCR products performed with specific oligonucleotides directed against ANP or GAPDH promoter regions were separated on the same agarose gel. ${ }^{*} P<0.05$ vs. control.

regions of $A N P$ and $B N P$, increasing $\mathrm{H} 3 \mathrm{~K} 9$ methylation status, and that this recruitment is lost with signal-responsive nuclear export of HDAC4. Furthermore, increased expression of H3K9-specific JMJC domain-containing demethylases may sustain these epigenetic modifications in the terminally failing human heart. These findings are summarized in Figure 11.

H3K9 demethylation as a rapid epigenetic modification in the heart. Although histone methylation was long considered to be an irreversible marker for silenced genes (12), recent reports revealed that histone demethylation can dynamically regulate gene expression. For instance, at 4 hours after LPS treatment, activation of proinflammatory genes in dendritic cells was associated with demethylation of $\mathrm{H} 3 \mathrm{~K} 9$ and recruitment of RNA polymerase II to the respective promoter regions (26). H3K9 demethylation correlated better with this recruitment than did acetylation of $\mathrm{H} 3$ and H4 (26), consistent with our present observation that demethylation of $\mathrm{H} 3 \mathrm{~K} 9$ was more prominent than $\mathrm{H} 3 \mathrm{~K} 9 \mathrm{ac}, \mathrm{H} 3 \mathrm{~K} 27 \mathrm{ac}$, or $\mathrm{H} 4 \mathrm{~K} 91 \mathrm{ac}$ in human failing myocardium. Furthermore, our experiments using isolated working hearts indicated that $\mathrm{H} 3 \mathrm{~K} 9$ was rapidly demethylated within 30 minutes in response to elevated cardiac preload, supporting the dynamic nature of $\mathrm{H} 3 \mathrm{~K} 9$ methylation as an epigenetic control mechanism of ANP and BNP in the heart. In contrast, $\mathrm{H} 3 \mathrm{~K} 4$ methylation was unchanged in failing hearts, in agreement with a recent study on adult cardiac myocytes in which reduction of overall $\mathrm{H} 3 \mathrm{~K} 4$ levels by deletion of PAX interacting protein 1, a key component of the H3K4 complex, did not affect $B N P$ expression and had only a small - and, paradoxically, activating - effect on ANP expression (36).

Role ofJMJC domain-containing demethylases in heart failure. A potential mechanism that could explain demethylation of $\mathrm{H} 3 \mathrm{~K} 9$ in the $A N P$ and $B N P$ promoter regions in failing hearts is upregulation of the H3K9-specific demethylases JMJD1A, JMJD2A, and JMJD2B. Expression of JMJD1A correlated inversely with $\mathrm{H} 3 \mathrm{~K} 9 \mathrm{me} 2$ levels and positively with upregulation of both $A N P$ and $B N P$ in failing hearts. These data are in line with previous results in smooth muscle cells, in which increased expression of JMJD1A was associated with decreased global levels of demethylated $\mathrm{H} 3 \mathrm{~K} 9$ and activation of several smooth muscle-specific genes (37).

Although knockdown of JMJD1A alone was compensated for by increased JMJD2A expression and had no effect on baseline ANP expression in neonatal cardiac myocytes (data not shown), double knockdown of both JMJD1A and JMJD2A reduced ANP and BNP expression by increasing $\mathrm{H} 3 \mathrm{~K} 9 \mathrm{me} 2$ and $\mathrm{H} 3 \mathrm{~K} 9 \mathrm{me} 3$. Since expression of JMJD1A and JMJD2A was 4- and 9-fold higher, respectively, and basal H3K9me2 and H3K9me3 were approximately 2-fold reduced in neonatal compared with adult cardiac myocytes, it may be possible that these JMJC domain-containing demethylases play a regulatory role in cardiac development by controlling the fetal gene program through control of $\mathrm{H} 3 \mathrm{~K} 9$ methylation. Furthermore, concerted upregulation of JMJD1A and JMJD2A could - to a certain extent - contribute to the reactivation of the fetal gene program in patients with heart failure.

In addition to $J M J D 1 A, J M J D 2 A$, and $J M J D 2 B$ were also upregulated in human failing hearts, and recruitment of JMJD2A to the promoter region of $A N P$ was increased in myocardium from patients with ICM, but not DCM. A recent study revealed that JMJD2A plays an important role in the development of cardiac hypertrophy and failure (30). A major target of JMJD2A demethylase activity was the promoter region of FHL1, a component of the mechanotransducer machinery in the heart that can induce cardiac hypertrophy via a pathway that involves serum response factor (SRF) and myocardin (30). Since ANP is also an SRF/myocardin target gene, JMJD2A augmented ANP expression in response to myocardin in an SRF-sensitive manner (30). These data support a regulatory role of $J M J D 2 A$ for reactivation of $A N P$ and $B N P$ in the failing heart.

However, several observations suggest that JMJC domain-containing demethylases may play a modulatory rather than a primary role for the reactivation of fetal genes in the failing heart. 
A

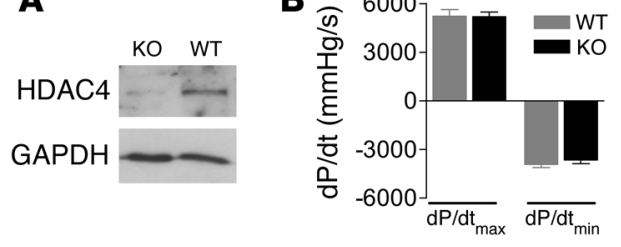

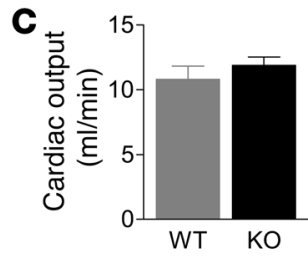
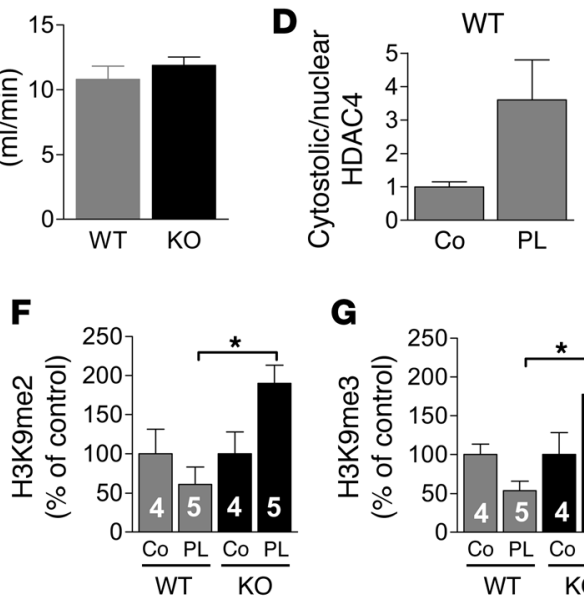

G
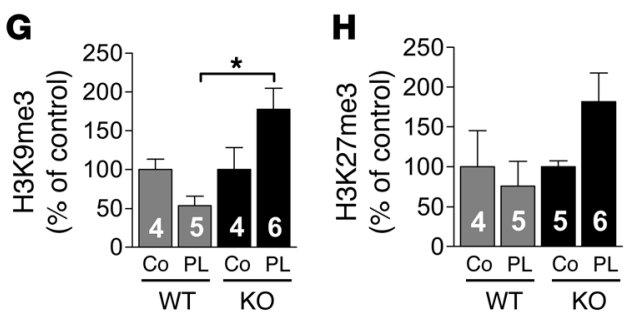

I

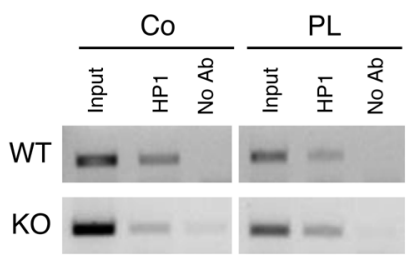

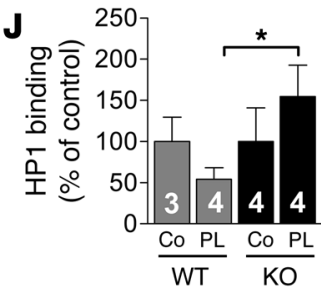

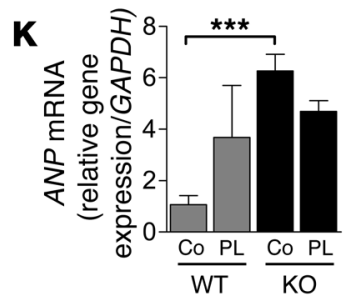

\section{Figure 9}

HDAC4 controls H3K9 demethylation of - and HP1 dissociation from — the ANP promoter region in response to elevated preload. (A) Western blot analysis of HDAC4 protein expression in hearts of HDAC4-KO mice versus WT littermates. Isolated working heart analysis of $d p / d t_{m a x}$ and $d p / d t_{\min }$ (B) as well as cardiac output (C) in WT and HDAC4-KO hearts under physiological load conditions (10 mmHg preload, $80 \mathrm{mmHg}$ afterload). (D) Cumulative results $(n=4)$ of nucleo-cytoplasmic shuttling of HDAC4 in WT mice after 60 minutes of increased preload versus control conditions. Representative (E) and cumulative (F-H) results of ChIP assay experiments probing for H3K9me2, H3K9me3, H3K27me2 (not shown), and H3K27me3. Representative (I) and cumulative ( $\mathbf{J}$ ) results for binding of HP1 to the ANP promoter region in WT and HDAC4-KO hearts after 60 minutes of elevated preload versus control conditions. Lanes in I were run on the same gel but were noncontiguous (white lines). ANP mRNA expression in WT and HDAC4-KO hearts after 60 minutes of increased preload versus control conditions ( $n=3-6$ experiments) (K). ChIP assay experiments on WT and HDAC4-KO hearts with normal and elevated preload were performed at the same time with identical conditions, and amplified PCR products performed with specific oligonucleotides directed against ANP promoter region were separated on the same agarose gel. In $\mathbf{F}-\mathbf{H}$ and $\mathbf{J}$, the number of experiments for each group is shown within the bars. ${ }^{*} P<0.05,{ }^{* \star *} P<0.001, \mathrm{HDAC} 4-\mathrm{KO}$ vs. WT.

First, while JMJD2A knockdown by $80 \%$ reduced baseline expression of FHL1 by approximately $75 \%$ in neonatal cardiac myocytes, ANP expression, which was 80 -fold higher in neonatal versus adult cardiac myocytes (Figure 6A), was not reduced under baseline conditions in the study by Zhang et al. (30). Second, the effect of double knockdown of JMJD1A and JMJD2A on ANP expression in neonatal cardiac myocytes was rather small (13\%-15\%; Figure 6E). Third, in response to pressure overload in mice, ANP expression increased 40-fold without a change of JMJD1A and JMJD2A expression (Figure 7). Finally, in response to an acute increase of preload in mouse hearts, H3K9 was demethylated without an increase of $J M J D 2 A$ expression or recruitment to the ANP promoter region (Figure 8 and Supplemental Figure 6). Thus, we considered additional mechanisms that may account for $\mathrm{H} 3 \mathrm{~K} 9$ demethylation in human heart failure.

Central role of HDAC4 for $\mathrm{H} 3 \mathrm{~K} 9$ demethylation. Methylation of histones is governed by G9a, SUV39H1, and several other methylases $(9,22)$. SUV39H1 selectively methylates H3K9, which generates a binding site for $\operatorname{HP} 1(11,38)$ and favors the formation of densely packed heterochromatin. Although overall SUV39H1 expression was unchanged in human failing hearts, H3K9 demethylation was closely associated with nucleo-cytoplasmic shuttling of HDAC4 and HP1 dissociation from the promoter regions of $A N P$ and $B N P$. Our findings in mice with cardiomyocyte-specific deletion of Hdac4 indicated that HDAC4 plays a causal role in controlling H3K9 demethylation in - and HP1 dissociation from - the ANP promoter region and, thus, ANP upregulation in response to increased hemodynamic load. As a potential underlying mechanism, the results in cell systems indicate that HDAC4 undergoes colocalization and protein-protein interaction with the histone methyltransferase SUV39H1 in the nucleus, providing a mechanism how HDAC4 could control H3K9 methylation. The isoform CaMKIISB is abundantly expressed in the heart, located in the nucleus, and specifically docks to and phosphorylates HDAC4 (17). In the present study, we found that constitutively active CaMKIISB disrupted the interaction between HDAC4 and SUV39H1 by triggering nucleo-cytosolic export of HDAC4, while SUV39H1 remained in the nucleus. Although these data do not prove causality, they nevertheless support the concept of a multiprotein complex consisting of HDAC4, SUV39H1, and HP1 (33, 34) that governs H3K9 methylation. Furthermore, in concert with previously reported results with CaMKI (33), our findings may extend this concept to signal responsiveness to CaMKIIסB, a CaM$\mathrm{KII}$ isoform that selectively targets HDAC4 (17) and is known to be 
A

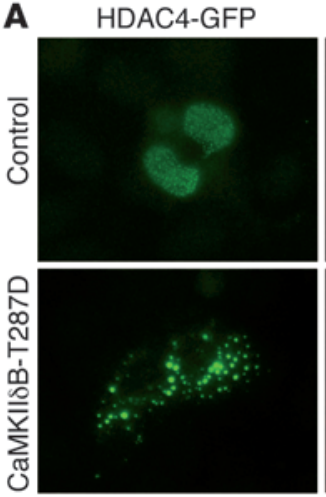

B

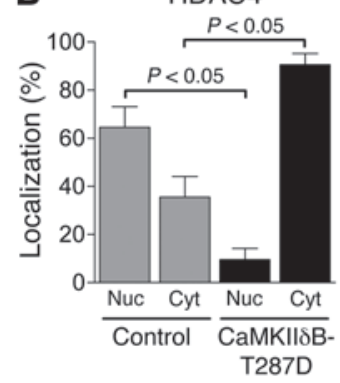

SUV39H1 TexasRed
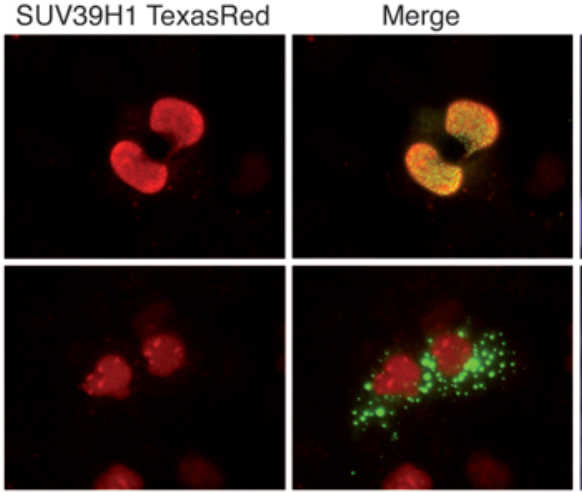

C

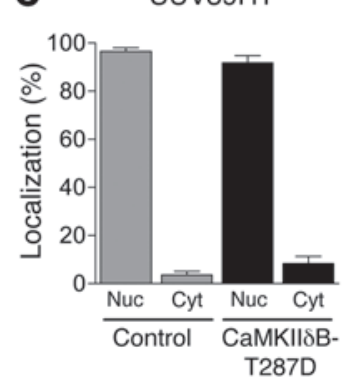

D

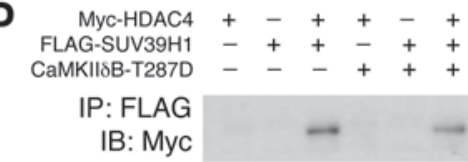

SUV39H1 input

IB: FLAG

HDAC4 input
IB: Myc

CaMKII input

IB: Myc
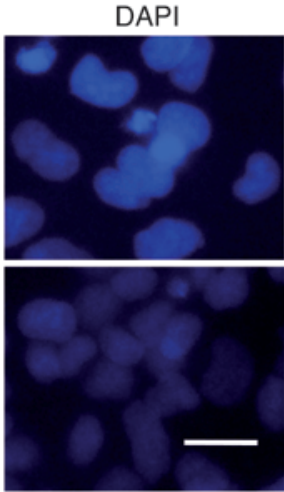

E

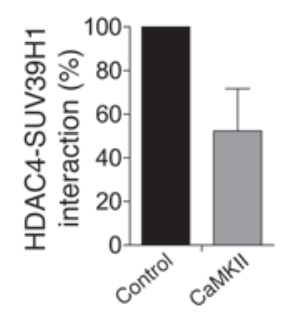

\section{Figure 10}

Direct interaction of HDAC4 with SUV39H1 is disrupted by CaMKII\&B-induced nuclear export of HDAC4. (A) COS cells were transfected with GFP-tagged HDAC4 and FLAG-tagged SUV39H1 (with secondary Texas Red-coupled antibodies), in the absence (control) and presence of CaMKIISB-T287D. Scale bar: $25 \mu \mathrm{m}$. Quantification of nuclear and cytosolic localization of HDAC4 (B) and SUV39H1 (C) in the absence and presence of CaMKIISB-T287D ( $n=4$ per group). (D) HEK293T cells were transfected with FLAG-tagged SUV39H1 and Myc-tagged HDAC4 in the absence and presence of CaMKIISB-T287D. Top: IP with FLAG, IB with Myc. Middle: IB against FLAG of the SUV39H1 input. Bottom: IB against Myc of HDAC4 input. (E) Cumulative densitometric results of 3 co-IP experiments determining HDAC4-SUV39H1 interaction (expressed relative to Myc input).

causally involved in the development of cardiac hypertrophy and failure in response to pressure overload (39).

Summary and conclusions. Our results indicate that reactivation of the fetal gene program in human heart failure is associated with epigenetic remodeling in the promoter regions of $A N P$ and BNP. Despite nuclear export of HDAC4, ANP and $B N P$ gene activation did not require increased histone acetylation in these promoter regions. In contrast, dynamic demethylation of H3K9 and dissociation of HP1 from the promoter regions were controlled by HDAC4, possibly by forming a transcriptional repressor complex with SUV39H1 that is disrupted by CaMKIISB-induced phosphorylation of HDAC4 (Figure 11). Furthermore, upregulation of JMJC domain-containing demethylases may sustain $\mathrm{H} 3 \mathrm{~K} 9$ demethylation in the course of heart failure. These findings improve our understanding of the dynamic epigenetic regulatory pathways in human heart failure and may help to identify novel targets to improve the treatment of patients with heart failure.

\section{Methods}

Human tissue. Human failing myocardium was obtained from patients with ICM $(n=8)$ or DCM $(n=8)$. 8 donor hearts of patients with no signs of heart disease that could not be used for transplantation due to $\mathrm{ABO}$ mismatch were used as nonfailing controls. See Supplemental Table 1 for clinical parameters and medication of patients with ICM and DCM.
Animal studies. Animals were housed under standard conditions with a 12-hour light/12-hour dark cycle and free access to water and chow. For working heart experiments, male CD1 mice (Charles River Laboratories) were used at 7 weeks of age. For TAC experiments, C57BL/6NCrl mice (Charles River) were used at 21-23 g BW. Conditional mutant mice with cardiac-specific Hdac4 deletion were generated by crossing existing floxed $H d a c 4$ mice (Hdac $4^{\text {loxp } / l o x p}$; ref. 40) to transgenic mice expressing Cre recombinase under the control of the $\alpha-M H C$ promoter (Hdac4loxP/loxP; $\alpha-M H C-C r e$; ref. 41) on a $129 \mathrm{SvEv} / \mathrm{C} 57 \mathrm{BL} / 6$ mixed background. From this intercross, male $H d a c 4^{\text {loxP/loxP }}$ and $H \operatorname{dac}^{\text {loxP/loxP }} ; \alpha-M H C$-Cre mice were used for subsequent experiments.

Working heart experiments. Working heart experiments were performed as described previously (42). Briefly, hearts were perfused with Krebs-Henseleit solution at $37^{\circ} \mathrm{C}$ in a Langendorff apparatus, paced at $400 \mathrm{bpm}$, and exposed to effective preload of $10 \mathrm{mmHg}$ and afterload of $80 \mathrm{mmHg}$. LV systolic and diastolic function was recorded via a high-fidelity conductance catheter (1.4 F SPR-839, $12 \mathrm{~mm}$ spacing; Millar) inserted into the LV cavity by apical puncture. Cardiac load conditions were varied by increasing either preload from 10 to $30 \mathrm{mmHg}$ or afterload from 80 to $120 \mathrm{mmHg}$. Preload and afterload groups were compared with a third control group in which preload and afterload were maintained at physiological levels $(10 \mathrm{mmHg}$ preload, 80 $\mathrm{mmHg}$ afterload). After 30, 60, and 90 minutes, hearts were snap-frozen and stored for further analysis. See Supplemental Methods for details.

TAC. TAC was performed in male C57BL/6NCrl mice (21-23 g BW) as described previously (43). The aorta was constricted by $65 \%-70 \%$ for 


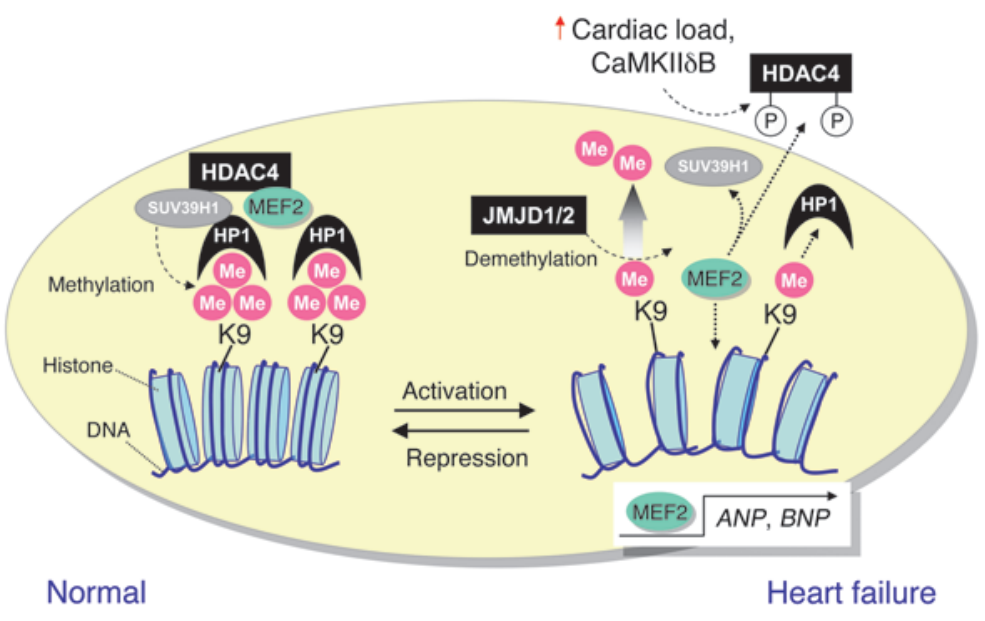

Figure 11

Epigenetic remodeling in human heart failure. Increased cardiac preload and/or activated CaMKIISB induce nucleo-cytoplasmic shuttling of HDAC4 and dissociation of its corepressor complex with SUV39H1 and HP1. This relieves H3K9me3, chromatin condensation, and repression of ANP and BNP gene transcription in response to MEF2. Upregulation of JMJD1 and JMJD2 sustains these epigenetic changes in the terminally failing heart.

6 weeks using a 27-gauge needle. Control animals underwent a sham operation without aortic ligation.

Western blot analysis. Western blot analysis was performed by standard methods on cytosolic and nuclear protein fractions of human LV and mouse myocardium as described previously (44) using antibodies against HDAC4, GAPDH, REST, and mRNA polymerase II. See Supplemental Methods for details.

$R N A$ isolation, reverse transcription, and real-time PCR. See Supplemental Methods and Supplemental Tables 2, 3, and 6.

ChIP assays. Briefly, after chromatin isolation, IP was performed with antibodies against H3K9ac, H3K27ac, H4K91ac, H3K4me2, H3K4me3, H3K9me2, H3K9me3, H3K27me3, HP1, JMJD1A, JMJD2A, G9a, LSD1, SUV39H1, and REST. The quantity of genomic DNA specifying the promoter regions of $A N P, B N P$, and GAPDH in the immunocomplexes were assessed by quantitative PCR. See Supplemental Tables 4 and 5 for primer sequences. For all experiments in human myocardium, tissues from patients with DCM and ICM were compared with nonfailing control tissues at the same time, under identical experimental conditions. PCRproducts obtained from the $A N P, B N P$, or GAPDH promoter region were separated on $2 \%$ agarose gels. Similar conditions applied to experiments on mouse hearts and rat neonatal cardiac myocytes: all experimental conditions were handled under identical conditions as described above. See complete unedited blots in the supplemental material. Because no differences were found between ICM and DCM tissue in most analyses, unless otherwise indicated, the cumulative data of ICM and DCM were merged into the single failing myocardium group. See Supplemental Methods for details.

Primary neonatal rat cardiac myocytes. Hearts of 3- to 5-day-old SpragueDawley rats were removed, and the ventricles were dissected, digested in ADS buffer (116 mmol/1 NaCl; 20 mmol/l HEPES; 0.8 mmol/1 Na $\mathrm{HPO}_{4}$; $5.6 \mathrm{mmol} / \mathrm{l}$ glucose; $5.4 \mathrm{mmol} / 1 \mathrm{KCl} ; 0.8 \mathrm{mmol} / 1 \mathrm{MgSO}_{4} \times 7 \mathrm{H}_{2} \mathrm{O}, \mathrm{pH} 7.35$; $0.6 \mathrm{mg} / \mathrm{ml}$ pankreatin; $0.5 \mathrm{mg} / \mathrm{ml}$ collagenase type 2 ) at $37^{\circ} \mathrm{C}$, and gently agitated in a bath shaker $(86 \mathrm{rpm})$ in several steps. All supernatants were collected, and the cells were preplated in F10 medium (Gibco, Invitrogen) plus $10 \%$ horse serum, $5 \%$ FCS, and $1 \%$ penicillin/streptomycin to deplete contamination by nonmyocardial cells. After 45 minutes, the still-suspended myocardial cells were removed from the attached nonmyocardial cells, counted using a Neubauer counting chamber, and plated at a density of $1.65-1.75 \times 10^{6}$ cells per 60-mm culture dish (BD Primaria).

Cultivation of cardiac myocytes and siRNA transfection. Neonatal rat cardiac myocytes were cultured under standard conditions $\left(37^{\circ} \mathrm{C}, 5 \% \mathrm{CO}_{2}\right)$ in serum-containing $\mathrm{F} 10$ medium as described above. Transfection was performed with $20 \mathrm{nM}$ predesigned siRNAs for JMJD1A and/or JMJD2A (Rn_Jmjd1a_3 and Rn LOC313539_1; Qiagen) and custom-designed scrambled control siRNAs (scr1a, 5'-CUCACCGAUUACCGUACUATT-3'; scr2a, 5'-GCUCGAAACGCCUAUAGAATT-3'; Qiagen) using HiPerfect Transfection Reagent (7.5 $\mu$ l per transfection; Qiagen) according to the manufacturer's protocol.

Isolation of adult rat cardiac cells. Adult rat cardiomyocytes were isolated with a protocol similar to that previously described for guinea pig myocytes (45). After centrifugation, supernatant was discarded, and cells were applied for RNA isolation using peqGold TriFast following the manufacturer's protocol (Peqlab).

Immunohistochemistry. Immunostaining was performed as described previously (17). Briefly, COS cells were grown on coverslips in DMEM plus 10\% FCS and 1\% penicillin/streptomycin; transfected with GFP-tagged HDAC4 (750 ng), FLAGtagged SUV39H1 (750 ng), or myc-tagged CaMKIIסB-T287D (400 ng) using GeneJammer (Agilent) according to the manufacturer's protocol; fixed after 48 hours; permeabilized; and blocked. Primary antibody against FLAG (rabbit anti-FLAG; Sigma-Aldrich) was used at a dilution of 1:200, secondary antibody (Texas Red anti-rabbit; vector) was used at a dilution of 1:400. All images were captured with a $\times 40$ objective.

Co-IP. Co-IP was performed as described previously (17). Briefly, HEK293T cells were transfected with myc-tagged HDAC4 (1 $\mu \mathrm{g})$, FLAGtagged SUV39H1 $(1 \mu \mathrm{g})$, or myc-tagged CaMKIISB-T287D (0.8 $\mu \mathrm{g})$; harvested after 48 hours; and disrupted with a 25 -gauge needle. Cell debris was removed by centrifugation, after which FLAG-tagged proteins were subjected to IP with M2-agarose conjugate (Sigma-Aldrich) and washed. Bound proteins were resolved by SDS-PAGE, and IBs were performed as indicated with anti-Myc antibody (A-14; Santa Cruz Biotechnology Inc.) and anti-FLAG antibody (M2; Sigma-Aldrich). Proteins were visualized using a chemiluminescense system (GE Healthcare).

Statistics. Data are presented as mean \pm SEM. Differences between groups were calculated by unpaired Student's 2-tailed $t$ test or 1-way ANOVA where appropriate. Regression analysis was performed using GraphPad Prism (version 3.00 for Windows; GraphPad Software). A $P$ value less than 0.05 was considered significant.

Study approval. Human studies were conducted according to the Declaration of Helsinki and approved by the local ethics committee (Ärztekammer des Saarlandes no. 131/00). All patients gave informed consent. Animal studies conformed to NIH guidelines (Guide for the Care and Use of Laboratory Animals. NIH publication no. 85-23. Revised 1996) and were approved by the local ethics committee.

\section{Acknowledgments}

We thank Eric N. Olson for helpful advice on the manuscript and Michelle Gulentz, Jeannette Zimolong, and Lisa Lang for technical assistance. The study was supported by the DFG (Emmy Noether Programm to C. Maack and J. Backs; KFO-196 to C. Maack and M. Böhm; SFB-894 to C. Maack), Hans und Gertie Fischer-Stiftung (to M. Böhm, M. Hohl, and J.-C. Reil), and Kompetenznetz Herzinsuffizienz of the Bundesministerium für Bil- 
dung und Forschung (BMBF; to M. Böhm). J. Backs is supported by the DZHK and by the BMBF.

Received for publication October 22, 2012, and accepted in revised form January 3, 2013.

1. Kannel WB. Incidence and epidemiology of heart failure. Heart Fail Rev. 2000;5(2):167-173.

2. Heineke J, Molkentin JD. Regulation of cardiac hypertrophy by intracellular signalling pathways. Nat Rev Mol Cell Biol. 2006;7(8):589-600.

3. Saito Y, et al. Augmented expression of atrial natriuretic polypeptide gene in ventricle of human failing heart. J Clin Invest. 1989;83(1):298-305.

4. Feldman AM, Ray PE, Silan CM, Mercer JA, Minobe W, Bristow MR. Selective gene expression in failing human heart. Quantification of steady-state levels of messenger RNA in endomyocardial biopsies using the polymerase chain reaction. Circulation. 1991;83(6):1866-1872.

5. Kögler $\mathrm{H}$, et al. Relevance of brain natriuretic peptide in preload-dependent regulation of cardiac sarcoplasmic reticulum Ca2+ ATPase expression. Circulation. 2006;113(23):2724-2732.

6. Lorch Y, LaPointe JW, Kornberg RD. Nucleosomes inhibit the initiation of transcription but allow chain elongation with the displacement of histones. Cell. 1987;49(2):203-210.

7. Lee DY, Hayes JJ, Pruss D, Wolffe AP. A positive role for histone acetylation in transcription factor access to nucleosomal DNA. Cell. 1993;72(1):73-84.

8. Backs J, Olson EN. Control of cardiac growth by histone acetylation/deacetylation. Circ Res. 2006; 98(1):15-24.

9. Shi Y, Whetstine JR. Dynamic regulation of histone lysine methylation by demethylases. Mol Cell. 2007;25(1):1-14.

10. Barski A, et al. High-resolution profiling of histone methylations in the human genome. Cell. 2007 . 129(4):823-837.

11. Bannister AJ, et al. Selective recognition of methylated lysine 9 on histone H3 by the HP1 chromo domain. Nature. 2001;410(6824):120-124.

12. Jenuwein T, Allis CD. Translating the histone code. Science. 2001;293(5532):1074-1080.

13. Haberland M, Montgomery RL, Olson EN. The many roles of histone deacetylases in development and physiology: implications for disease and therapy. Nat Rev Genet. 2009;10(1):32-42.

14. Zhang CL, McKinsey TA, Chang S, Antos CL, Hill JA, Olson EN. Class II histone deacetylases act as signal-responsive repressors of cardiac hypertrophy. Cell. 2002;110(4):479-488.

15. Chang S, McKinsey TA, Zhang CL, Richardson JA, Hill JA, Olson EN. Histone deacetylases 5 and 9 govern responsiveness of the heart to a subset of stress signals and play redundant roles in heart development. Mol Cell Biol. 2004;24(19):8467-8476.

16. McKinsey TA, Zhang CL, Lu J, Olson EN. Signaldependent nuclear export of a histone deacetylase regulates muscle differentiation. Nature. 2000;408(6808):106-111.

17. Backs J, Song K, Bezprozvannaya S, Chang S, Olson
Address correspondence to: Christoph Maack, Universitätsklinikum des Saarlandes, Klinik für Innere Medizin III, 66421 Homburg, Germany. Phone: 49.6841.1621380; Fax: 49.6841.1623434; E-mail: christoph.maack@uks.eu.
EN. CaM kinase II selectively signals to histone deacetylase 4 during cardiomyocyte hypertrophy. J Clin Invest. 2006;116(7):1853-1864.

18. Wu X, et al. Local InsP3-dependent perinuclear $\mathrm{Ca}^{2+}$ signaling in cardiac myocyte excitation-transcription coupling. J Clin Invest. 2006;116(3):675-682.

19. Ago T, et al. A redox-dependent pathway for regulating class II HDACs and cardiac hypertrophy. Cell. 2008;133(6):978-993.

20. Miska EA, Karlsson C, Langley E, Nielsen SJ, Pines J, Kouzarides T. HDAC4 deacetylase associates with and represses the MEF2 transcription factor. EMBO J. 1999;18(18):5099-5107.

21. Lu J, McKinsey TA, Nicol RL, Olson EN. Signaldependent activation of the MEF2 transcription factor by dissociation from histone deacetylases. Proc Natl Acad Sci U S A. 2000;97(8):4070-4075.

22. Martin C, Zhang Y. The diverse functions of histone lysine methylation. Nat Rev Mol Cell Biol. 2005; 6(11):838-849.

23. Shi Y, et al. Histone demethylation mediated by the nuclear amine oxidase homolog LSD1. Cell. 2004;119(7):941-953.

24. Tsukada Y, et al. Histone demethylation by a family of JmjC domain-containing proteins. Nature. 2006;439(7078):811-816.

25. Bannister AJ, Kouzarides T. Reversing histone methylation. Nature. 2005;436(7054):1103-1106.

26. Saccani S, Natoli G. Dynamic changes in histone H3 Lys 9 methylation occurring at tightly regulated inducible inflammatory genes. Genes Dev. 2002;16(17):2219-2224.

27. Brasacchio D, et al. Hyperglycemia induces a dynamic cooperativity of histone methylase and demethylase enzymes associated with gene-activating epigenetic marks that coexist on the lysine tail. Diabetes. 2009;58(5):1229-1236.

28. Villeneuve LM, Reddy MA, Lanting LL, Wang M, Meng L, Natarajan R. Epigenetic histone H3 lysine 9 methylation in metabolic memory and inflammatory phenotype of vascular smooth muscle cells in diabetes. Proc Natl Acad Sci U S A. 2008; 105(26):9047-9052.

29. Kaneda R, et al. Genome-wide histone methylation profile for heart failure. Genes Cells. 2009;14(1):69-77.

30. Zhang OJ, Chen HZ, Wang L, Liu DP, Hill JA, Liu $\mathrm{ZP}$. The histone trimethyllysine demethylase JMJD2A promotes cardiac hypertrophy in response to hypertrophic stimuli in mice. J Clin Invest. 2011; 121(6):2447-2456.

31. Kuwahara K, et al. NRSF regulates the fetal cardiac gene program and maintains normal cardiac structure and function. EMBOJ. 2003;22(23):6310-6321.

32. Ooi L, Wood IC. Chromatin crosstalk in development and disease: lessons from REST. Nat Rev Genet. 2007;8(7):544-554.

33. Zhang CL, McKinsey TA, Olson EN. Association of class II histone deacetylases with heterochromatin protein 1: potential role for histone methylation in control of muscle differentiation. Mol Cell Biol. 2002; 22(20):7302-7312.

34. Aagaard L, et al. Functional mammalian homologues of the Drosophila PEV-modifier Su(var)3-9 encode centromere-associated proteins which complex with the heterochromatin component M31. EMBO J. 1999;18(7):1923-1938.

35. Kirchhefer U, Schmitz W, Scholz H, Neumann J. Activity of cAMP-dependent protein kinase and $\mathrm{Ca}^{2+} /$ calmodulin-dependent protein kinase in failing and nonfailing human hearts. Cardiovasc Res. 1999;42(1):254-261.

36. Stein AB, et al. Loss of H3K4 methylation destabilizes gene expression patterns and physiological functions in adult murine cardiomyocytes. J Clin Invest. 2011;121(7):2641-2650.

37. Lockman K, Taylor JM, Mack CP. The histone demethylase, Jmjd1a, interacts with the myocardin factors to regulate SMC differentiation marker gene expression. Circ Res. 2007;101(12):e115-123.

38. Lachner M, O'Carroll D, Rea S, Mechtler K, Jenuwein $\mathrm{T}$. Methylation of histone $\mathrm{H} 3$ lysine 9 creates a binding site for HP1 proteins. Nature. 2001; 410(6824):116-120.

39. Backs J, et al. The delta isoform of CaM kinase II is required for pathological cardiac hypertrophy and remodeling after pressure overload. Proc Natl Acad Sci U S A. 2009;106(7):2342-2347.

40. Potthoff MJ, et al. Histone deacetylase degradation and MEF2 activation promote the formation of slow-twitch myofibers. J Clin Invest. 2007; 117(9):2459-2467.

41. Agah R, Frenkel PA, French BA, Michael LH, Overbeek PA, Schneider MD. Gene recombination in postmitotic cells. Targeted expression of Cre recombinase provokes cardiac-restricted, site-specific rearrangement in adult ventricular muscle in vivo. J Clin Invest. 1997;100(1):169-179.

42. Reil JC, et al. Cardiac Rac1 overexpression in mice creates a substrate for atrial arrhythmias characterized by structural remodelling. Cardiovasc Res. 2010;87(3):485-493.

43. Custodis F, Eberl M, Kilter H, Böhm M, Laufs U. Association of RhoGDIalpha with Rac1 GTPase mediates free radical production during myocardial hypertrophy. Cardiovasc Res. 2006;71(2):342-351.

44. Maack C, Dabew ER, Hohl M, Schäfers HJ, Böhm $M$. Endogenous activation of mitochondrial $K_{\mathrm{ATP}}$ channels protects human failing myocardium from hydroxyl radical-induced stunning. Circ Res. 2009;105(8):811-817.

45. Kohlhaas M, Maack C. Adverse bioenergetic consequences of $\mathrm{Na}^{+}-\mathrm{Ca}^{2+}$ exchanger-mediated $\mathrm{Ca}^{2+}$ influx in cardiac myocytes. Circulation. 2010; 122(22):2273-2280 